\title{
BATATA INGLESA MINIMAMENTE PROCESSADA: ESTABILIDADE DE TEXTURA E COR
}

\author{
B. W. BÖHMER ${ }^{1}$, P. C. ALVES ${ }^{1}$, C. C. da CUNHA ${ }^{1}$, L. K. SCHEIK ${ }^{1}$, J. D. F. da SILVA ${ }^{1},{ }^{1}$, \\ C. D. BORGES ${ }^{1}$, M. A. GULARTE ${ }^{1}$, C. R. B. MENDONÇA ${ }^{1}$ \\ ${ }^{1}$ Universidade Federal de Pelotas, Centro de Ciências Químicas Farmacêuticas e de Alimentos \\ patycascaes2008@hotmail.com,bruna_bohmer@yahoo.com.br, cha.cunha@hotmail.com, \\ leticiascheik@hotmail.com,dilson13@gmail.com, caroldellin@hotmail.com; \\ marciagularte@hotmail.com; carlaufpel@hotmail.com
}

RESUMO - Objetivou-se avaliar a estabilidade física da batata (variedade) minimamente processada submetida a diferentes tratamentos, onde foram analisados os parâmetros de textura e cor. O tubérculo foi submetido ao processamento mínimo e posteriormente tratado com variados agentes antioxidantes. A avaliação foi realizada durante um período de 12 dias. Os resultados de textura demonstraram que para amostra tratada com ácido ascórbico ocorreu redução da firmeza e aumento da elasticidade, já aquelas tratadas com ácido cítrico comportaram-se semelhantemente à tratada com bissulfito, onde ocorreu aumento da firmeza e redução da elasticidade, o tratamento com sorbato apresentou resultado semelhante ao obtido para a amostra controle com vácuo, com elevação da firmeza e também da elasticidade ao passar do tempo de armazenamento. A amostra controle sem vácuo foi a única que não apresentou semelhança de comportamento, com redução de firmeza e elasticidade.

\section{INTRODUÇÃO}

A tendência de aumento da alimentação fora de casa, a considerável elevação na quantidade de mulheres trabalhando fora e também de pessoas que moram sozinhas, aliados a preocupação com uma vida mais saudável, têm motivado o mercado de produtos minimamente processados. Assim, frutas e hortaliças minimamente processadas têm ganhado cada vez mais espaço nas gôndolas de supermercados, pois aliam praticidade, variedade e qualidade (Tonet, 2001).

Cabe considerar, que os estresses mecânicos causados pelo processamento mínimo aumentam a taxa de reações bioquímicas responsáveis pelas mudanças de cor, sabor, textura e qualidade nutricional dos produtos minimamente processados (ROCHA et al., 2003).

A batata (Solanum tuberosum L.) é um tubérculo originário da região andina do continente sul-americano, tendo sido levada à Europa pelos espanhóis no século XVI. Por suas qualidades nutritivas e por adaptar-se facilmente aos vários tipos de solo, em pouco tempo seu consumo generalizou-se em todo o mundo. É considerada a hortaliça mais importante para a economia nacional (IBGE, 2002) 
A principal limitação do processo mínimo de batatas é a alta susceptibilidade ao escurecimento oriundo de reações catalisadas por enzimas, destacando-se a polifenoloxidase (PPO), as etapas de descascamento, corte ou fatiamento promovem o rompimento das estruturas celulares, permitindo o contato entre a enzima e os substratos. $\mathrm{O}$ escurecimento inicia-se na oxidação de compostos fenólicos, como produto tem-se a quinona que sofre condensação formando pigmentos escuros insolúveis, denominados melaninas, ou reage não enzimaticamente com outros compostos fenólicos, aminoácidos e proteínas, também formando melanina (ARAÚJO, 2003).

A enzima peroxidase (POD), também responsável pelo escurecimento em hortaliças minimamente processadas, está relacionada com processos de cicatrização. Robinson (1991) revisou as funções fisiológicas da POD na pós-colheita de frutas e hortaliças e atribuiu a ela muitas das funções oxidativas de fenóis, inclusive a síntese de lignina e suberina para reconstituição de tecidos vegetais lesionados. A POD promove a oxidação de compostos fenólicos na presença de peróxido de hidrogênio, apresentando possível ação sinergística com a PPO.

Diversas substâncias químicas, em diferentes combinações e concentrações, são eficazes para inibir as reações de escurecimento (Laurila et al., 1998). As mais utilizadas são os sulfitos e os ácidos, pelo baixo custo, facilidade na aplicação e efetividade do tratamento (Araújo, 2010). A manutenção da vida de prateleira dos produtos minimamente processados também depende da descontaminação microbiana (Gómez-López et al., 2009) e do uso de embalagens adequadas e de refrigeração (Rocculi et al., 2007). Na Europa, a vida de prateleira varia de 5 a 7 dias, enquanto que nos Estados Unidos varia de 10 a 14 dias (Jaouen, 2006).

Outras alterações decorrentes do processamento mínimo em batatas estão relacionadas com o aumento da atividade metabólica e com a descompartimentação de enzimas e substratos, podendo resultar em perda de firmeza, desenvolvimento de aromas e sabores desagradáveis (GUNES, et. al.; 1997).

Vários fatores afetam a intensidade da resposta ao estresse, como cultivar, estágio de maturação fisiológica, extensão da injúria, temperatura, concentrações de $\mathrm{O}_{2} \mathrm{e} \mathrm{CO}_{2}$ na atmosfera, pressão de vapor de água e vários inibidores, a refrigeração é a ferramenta mais eficiente para prolongar a vida útil, uma vez que as reações metabólicas são reduzidas de duas a três vezes para cada decréscimo de $10^{\circ} \mathrm{C}$ na temperatura (BRECHT, 1995).

Objetivou-se com este estudo testar a resposta de diferentes tratamentos na estabilidade de textura e cor físicas de batatas minimamente processadas.

\section{Metodologia}

A matéria-prima (batata inglesa) foi devidamente lavada, descascada, cortada em cubos e sanitizada com solução de dicloroisocianurato de sódio (2 g.L $\left.\mathrm{L}^{-1}\right)$ por 15 minutos; após executou-se o enxágue, tratamento, centrifugação e acondicionamento.

Os tratamentos empregados em solução aquosa foram: sorbato de sódio 0,05 \% (T1); bissulfito de sódio 0,01\% (T2); ácido cítrico $1 \%$ (T3); ácido ascórbico $1 \%$ (T4). Os respectivos tratamentos foram aplicados por um minuto. Após o tratamento e centrifugação as amostras foram 
acondicionadas em embalagens de polietileno de baixa densidade (PEBD). Para fins comparativos preparou-se uma amostra com a ausência de aditivos (T5). Todas as amostras foram armazenadas sob-refrigeração $\left(4^{\circ} \mathrm{C}\right)$ e as análises foram realizadas após $1,4,7$ e 12 dias de estocagem.

\subsection{Avaliações}

Realizaram-se avaliações físicas de cor e textura após 1, 4, 7 e 12 dias de armazenamento refrigerado das batatas.

$\mathrm{Na}$ análise de cor foram utilizados vinte cubos de batata, realizado 40 leituras em cada período de análise, ou seja, duas leituras em cada cubo. A cor foi determinada utilizando-se um colorímetro Minolta CR 400. Os valores $\mathrm{a}^{*}, \mathrm{~b}^{*}$ e $\mathrm{L}^{*}$ foram utilizados para calcular o Índice de Escurecimento (IE) de acordo com Palou et al. (1999), segundo a Equação 1:

$$
I E=\frac{[100(X-0,31)]}{0,172}
$$

Em que:

$$
X=\frac{(a *+1,75 L)}{(5,645+a *-3,02 b *)}
$$

$\mathrm{Na}$ análise de textura foram utilizados vinte cubos de batata, sendo realizada uma leitura em cada cubo, por amostra, em cada período de análise. As medidas de textura foram determinadas utilizando-se um texturômetro (Stable Micro Systens modelo TA.XTplus) e probe $\mathrm{P} / 2 \mathrm{~N}$. Os resultados foram expressos em firmeza e elasticidade.

\subsection{Análise Estatística}

O experimento foi em delineamento completamente casualizado. Os tratamentos foram arranjados em esquema fatorial. Os dados foram analisados quanto à normalidade pelo teste de Shapiro-Wilk e à homocedasticidade pelo teste de Hartley e, posteriormente submetidos à análise de variância e análise de regressão durante o tempo de armazenamento (SAS INSTITUTE, 2002).

\section{Resultados e Discussões}

Os dados obtidos foram analisados quanto à normalidade, à homocedasticidade e a independência dos resíduos foi verificada graficamente. Posteriormente, os dados foram submetidos à análise de variância, constatando-se significância estatística, foi aplicado o teste comparação de médias nos tratamentos através do teste tukey $(\mathrm{p} \leq 0,05)$.

Avaliando-se a cor ao longo do tempo de estocagem, por meio do índice de escurecimento (IE), constatou-se escurecimento significativo nas amostras tratadas com ácido cítrico, ácido ascórbico e controle sem vácuo, não mostrando o mesmo efeito as batatas tratadas com bissulfito, sorbato e controle com vácuo. Entretanto, apesar do escurecimento significativo da amostra com do ácido cítrico, este aditivo foi o que proporcionou a segunda 
menor variação do IE, sendo a menor variação a proporcionada pelo vácuo, estes valores são observados na tabela 1 .

Tabela 1- Dados referentes ao índice de escurecimento das batatas em função do tratamento aplicado.

\begin{tabular}{|c|c|c|r|r|r|r|}
\hline $\begin{array}{c}\text { Tempo de } \\
\text { estocagem }\end{array}$ & Ác. Cítrico & Ác. Ascórbico & Bissulfito & \multicolumn{1}{|l|}{ Sorbato } & \multicolumn{1}{l|}{ Vácuo } & \multicolumn{1}{|c|}{ Sem vácuo } \\
\hline 1 & $33,30 \mathrm{~b}$ & $31,81 \mathrm{~b}$ & $32,40 \mathrm{~b}$ & $33,52 \mathrm{~b}$ & $32,72 \mathrm{~b}$ & $36,36 \mathrm{a}$ \\
\hline 4 & $37,50 \mathrm{~b}$ & $36,87 \mathrm{~b}$ & $44,64 \mathrm{a}$ & $38,74 \mathrm{~b}$ & $37,28 \mathrm{~b}$ & $42,55 \mathrm{ab}$ \\
\hline 7 & $40,50 \mathrm{bc}$ & $44,50 \mathrm{a}$ & $45,50 \mathrm{ab}$ & $42,00 \mathrm{~b}$ & $38,00 \mathrm{c}$ & $44,55 \mathrm{a}$ \\
\hline 12 & $42,79 \mathrm{c}$ & $51,44 \mathrm{a}$ & $48,54 \mathrm{~b}$ & $43,97 \mathrm{c}$ & $39,70 \mathrm{~d}$ & $46,68 \mathrm{~b}$ \\
\hline
\end{tabular}

Letras distintas na linha diferem entre os tramentos de mesmo dia pelo teste de Tukey $(p<0,05)$.

Avaliando as variações no IE entre o primeiro e último dia $\left(12^{\circ}\right)$ de estocagem, observou-se que a amostra tratada com ácido ascórbico foi a que mostrou maior variação $(19,63)$, seguida da amostra com bissulfito $(16,14)$, com sorbato $(10,45)$, controle sem vácuo $(10,32)$, com ácido cítrico $(9,49)$ e controle com vácuo $(6,98)$, portanto, sendo este último o tratamento que demonstrou ser o mais eficiente para minimizar o escurecimento das batatas.

A eficácia do vácuo em relação ao controle da atividade de enzimas do escurecimento foi também verificada por Rocha et al. (2003), que avaliaram o efeito da embalagem a vácuo na manutenção da qualidade de batatas 'Desirée' minimamente processadas. Esses autores observaram um decréscimo de aproximadamente $50 \%$ na atividade da PPO ao longo dos sete dias de observação e verificaram, adicionalmente, que o vácuo foi eficaz no controle do escurecimento enzimático e de outras variáveis que conferem qualidade ao produto.

Conforme a tabela 2, pode-se observar que o longo dos doze dias de análise, observa-se um aumento na firmeza para todas as amostras, porém, novamente, sem diferença estatística entre tratamentos para o mesmo período.

Tabela 2 - Dados referentes aos parâmetros de textura (firmeza e elasticidade) das batatas em função do tratamento aplicado, expressos em Newton.

\begin{tabular}{|l|l|l|l|l|l|l|l|}
\hline \multirow{2}{*}{$\begin{array}{l}\text { Avaliação } \\
\text { Firmeza }\end{array}$} & Dias & Ácido ascórbic & Ácido cítrico & Bissulfito & Vácuo & Controle & Sorbato \\
\cline { 2 - 8 } & 1 & $1,95 \pm 0,33 \mathrm{~b}$ & $1,97 \pm 0,23 \mathrm{~b}$ & $2,11 \pm 0,36 \mathrm{~b}$ & $1,96 \pm 0,37 \mathrm{~b}$ & $2,75 \pm 0,58 \mathrm{a}$ & $1,91 \pm 0,36 \mathrm{~b}$ \\
\hline & 4 & $2,43 \pm 0,55 \mathrm{a}$ & $2,24 \pm 0,65 \mathrm{a}$ & $2,40 \pm 0,42 \mathrm{a}$ & $2,08 \pm 0,42 \mathrm{a}$ & $2,15 \pm 0,47 \mathrm{a}$ & $2,58 \pm 0,58 \mathrm{a}$ \\
\hline & 7 & $1,80 \pm 0,58 \mathrm{c}$ & $2,19 \pm 0,43 \mathrm{bc}$ & $2,35 \pm 0,43 \mathrm{~b}$ & $2,16 \pm 0,47 \mathrm{c}$ & $2,33 \pm 0,43 \mathrm{~b}$ & $2,51 \pm 0,44 \mathrm{a}$ \\
\hline & 12 & $1,80 \pm 0,58 \mathrm{~b}$ & $2,19 \pm 0,43 \mathrm{c}$ & $2,35 \pm 0,43 \mathrm{~b}$ & $2,28 \pm 0,38 \mathrm{ab}$ & $2,54 \pm 0,37 \mathrm{a}$ & $2,00 \pm 0,44 \mathrm{a}$ \\
\hline Elasticidade & 1 & $8,99 \pm 1,09 \mathrm{~b}$ & $8,95 \pm 0,7 \mathrm{~b}$ & $9,30 \pm 1,03 \mathrm{~b}$ & $8,96 \pm 1,90 \mathrm{~b}$ & $11,86 \pm 2,56 \mathrm{a}$ & $9,05 \pm 0,90 \mathrm{~b}$ \\
\hline & 4 & $9,4 \pm 1,72 \mathrm{a}$ & $8,57 \pm 1,43 \mathrm{~b}$ & $9,83 \pm 1,50 \mathrm{a}$ & $9,6 \pm 1,44 \mathrm{ab}$ & $8,51 \pm 1,4 \mathrm{~b}$ & $9,80 \pm 1,20 \mathrm{a}$ \\
\hline & 7 & $9,02 \pm 0,99 \mathrm{ab}$ & $8,8 \pm 1,06 \mathrm{~b}$ & $8,87 \pm 1,06 \mathrm{~b}$ & $8,80 \pm 1,60 \mathrm{~b}$ & $9,27 \pm 1,37 \mathrm{a}$ & $9,69 \pm 1,30 \mathrm{a}$ \\
\hline & 12 & $9,02 \pm 0,99 \mathrm{ab}$ & $8,8 \pm 1,06 \mathrm{~b}$ & $8,87 \pm 1,06 \mathrm{~b}$ & $9,86 \pm 1,06 \mathrm{a}$ & $9,73 \pm 0,92 \mathrm{a}$ & $9,69 \pm 1,30 \mathrm{a}$ \\
\hline
\end{tabular}

*média $(n=30)$, letras minúsculas distintas na linha diferem entre os tratamentos de mesmo dia pelo

teste de Tukey $(p<0,05)$. 
O corte e o descasque podem provocar a ativação de mecanismos de defesa, culminando na deposição de lignina e suberina nas paredes das células danificadas (Dyer et al., 1989; Dixon \& Paiva, 1995), possivelmente seguido da divisão celular sob o tecido suberizado para recomposição da periderme (Burton, 1982).

A lignificação após o dano é uma reação enzimática, envolvendo a atividade da fenilalanina amônia-liase em resposta ao estresse (Dixon \& Paiva, 1995).

Também é possível que o aumento da firmeza nas batatas seja devido à perda de água, evidenciada por superfície áspera e ressecada, observada nas amostras tratadas com ácido cítrico, bissulfito e sorbato.

Este aumento na firmeza também foi observado por Pineli et. al. (2005) que avaliou batatas "Ágata" que passaram pelo processo mínimo e foram armazenadas sob vácuo.

A elevação na velocidade da perda de água é o maior problema físico observado em frutas e hortaliças minimamente processadas. O corte ou descasque expõe os tecidos internos hidratados e aumenta drasticamente a taxa de evaporação de água. De acordo com Burton (1982) a diferença na taxa de perda de água entre um tecido que foi submetido a processamento e outro que não passou pelo mesmo processo varia de cinco até mais que 500 vezes em batatas, que são órgãos intensamente suberizados.

\section{CONCLUSÃO}

Batatas minimamente processadas apresentaram progressivo aumento no índice de escurecimento para todos os tratamentos aplicados, no entanto, dentre esses o que apresentou menor índice de escurecimento foi a amostra sob vácuo, foi observado também liberação de água nas embalagens, juntamente com elevação da firmeza que foi observada para todas amostras, sem diferir estatisticamente entre tratamentos durante o mesmo período de análise, quanto a elasticidade não foi constatada diferença significativa.

Frente ao exposto, observa-se então, a importância da busca de tratamentos alternativos que visam estender o frescor de um produto minimamente processado, uma vez que este torna-se mais susceptível a perda de qualidade, A associação de tratamentos antioxidantes com atmosferas modificadas deve ser avaliada como alternativa para obtenção de um produto mais estável no que diz respeito à firmeza, cor e aspecto de frescor. 


\section{REFERÊNCIAS}

ARAÚJO JM. Química de alimentos: teoria e prática. 4. Ed. Viçosa: UFV. 596 p. 2010.

ARAÚJO, J.M.A. de. Química de alimentos: teoria e prática.3.ed. Viçosa: Ed. da UFV, 2003. 475p.

BRECHT, J.K. Physiology of lightly processedfruits and vegetables. HortScience, v. 30, n. 1,p. 18-22, 1995.

CARLIN, F.; NUGYEN-THE, C.; HILBERT, G.;CHAMBROY, Y. Modified atmospherepackaging of fresh "ready-to-use" gratedcarrots in polymeric films. Journal of FoodScience, v. 55, n. 4, p. 1033-1038, 1990.

DUNDFORD, H.B.; STILLMAN, J.S. On the function and mechanism of action of peroxidases. Coord. Chem. Rev. v. 19, p. 187-251, 1976.

GÓMEZ-LÓPEZ VM; RAJKOVIC A; RAGAERT P; SMIGICN; DEVLIEGHERE F. Chlorine dioxide for minimally processed produce preservation: a review. Trends in Food Science \& Technology 20:17-26. 2009.

GUNES, G.; LEE, C.Y. Colour of minimally processed potatoes as affected by modified atmosphere and ant browning agents. Journal of Food Science, v. 62, p. 572-575 e 582, 1997.

JAOUEN N. 2006. Packaging ideas for fresh-cut products. In: Fresh-cut Europe: The new European fresh-cut conference. Disponível em: 〈http://www.freshcuteurope.com/〉. Acesso em 27 de março de 2014.

LAURILA E; KERVINEN R; AHVENAINEN R.1998. The inhibition of enzymatic browning in minimally processed vegetables and fruits. Postharvest News and information 9:5366. ROBINSON, D.S. Peroxidases and catalases in foods.In Oxidative Enzymes in Foods, ed. ROBINSON, D.S.; ESKIN, N.A.M. Elsevier Applied Science, London, p. 147, 1991.

PALOU, E.; LÓPEZ-MALO, A.; BARBOSA-CÁNOVAS, G. V.; WELTI-CHANES, J.; SWANSON, B. G. Polyphenoloxidase activity and color of blanched and high hydrostatic pressure treated banana puree. J. Food Sci., v.64, n. 1, p.42-45, 1999.

PINELI, L. L. O; MORETTI, L. C; ALMEIDA, C, G; ONUKI, A. C. A; NASCIMENTO, A. B G; Caracterização química e física de batatas 'Ágata' minimamente processadas, embaladas sob diferentes atmosferas modificadas ativas. Disponível em : <http://www.scielo.br/pdf/pab/v40n10/a13v4010.pdf>. Acesso em 05 de Maio de 2014.

ROCCULI P; GALINDO FG; MENDONZA F; WADSÖ L; ROMANI S; DALLA ROSA M; SJÖHOLM I. Effects of the application of anti-browning substances on the metabolic activity and 
sugar composition of fresh-cut potatoes.Phostharvest Biology and Technology 43:151-157. 2007.

ROCHA, A.M.C.N.; COULON, E.C.; MORAIS, A.M.M.B. Effectsof vacuum packaging on the physical quality of minimally processed potatoes. Food Service Technology, v.3, p.81-88, 2003. 